\title{
An assessment for health education and health promotion in chronic disease demonstration districts: a comparative study from Hunan Province, China
}

\author{
Qiaohua Xu ${ }^{1}$, Biyun Chen ${ }^{1}$, Donghui Jin ${ }^{1}$, Li Yin ${ }^{2}$, Li Yin ${ }^{1}$, Yuelong Huang ${ }^{\text {Corresp. } 1}$ \\ 1 Department of Chronic Diseases Control and Prevention, Hunan Provincial Center for Diseases Control and Prevention, Changsha, Hunan, China \\ 2 Chronic diseases control, Hunan Provincial Center for Diseases Control and Prevention, Changsha, Hunan, China \\ Corresponding Author: Yuelong Huang \\ Email address: ylh410@126.com
}

Background. As cost-effective strategies of chronic diseases control, integrated health education and health promotion play important roles in the program of chronic disease demonstration districts in China. The performance of these districts can be directly assessed by their health education and promotion work. However, few assessments have been reported here without proper quality indicators. This study was designed to establish a framework of indicators for outcome evaluation of health education and promotion efforts in Chinese districts, and explore the factors involved to promote the effort.

Methods. A modified two-round Delphi survey was first used to construct quality indicators on a ninepoint Likert scale. With those indicators, the rank sum ratio (RSR) method was then conducted through rank conversion and parametric statistics, to assess and classify the performance of ten districts or counties randomly chosen both from demonstration and non-demonstration districts in the Hunan province.

Results. The Delphi process produced 7 themes, 25 sub-themes items as quality indicators. The 7 themes included management of the organization, financial support, professional personnel, health education and promotion, residents' health awareness and behaviors, residents' satisfaction, and residents' health literacy. The districts were classified into four levels by RSR as follows: One demonstration district at the first-ranked level, five other demonstration districts at the second-ranked level, all non-demonstration districts at the third-ranked level. None were at the fourth-qualified level.

Discussion. Chronic disease demonstration districts performed better on the work of health education and health promotion than the non-demonstration districts. The work should be focused on the following measures of chronic diseases: management of the organization, financial support, media-related broadcasting, technical support, community-based promotion and supportive environment, and people's enhanced awareness and health literacy. 
3 An assessment for health education and health promotion in chronic

4 disease demonstration districts: a comparative study from Hunan

5 Province, China

6

7

8 Qiaohua $\mathrm{Xu}^{1}$, Biyun $\mathrm{Chen}^{1}$, Donghui Jin ${ }^{1}$, Li Yin ${ }^{1}$, Yuelong Huang ${ }^{1 *}$

9

10

11 Department of Chronic Diseases Control and Prevention, Hunan Provincial Center for Disease Control

12 and Prevention, Changsha, China.

13

$14 *$ Corresponding author

15 Email: ylh410@126.com.

16

17

18

19

20

21

22 


\section{Abstract}

24 Background. As cost-effective strategies of chronic diseases control, integrated health education

25 and health promotion play important roles in the program of chronic disease demonstration

26 districts in China. The performance of these districts can be directly assessed by their health

27 education and promotion work. However, few assessments have been reported here without

28 proper quality indicators. This study was designed to establish a framework of indicators for

29 outcome evaluation of health education and promotion efforts in Chinese districts, and explore

30 the factors involved to promote the effort.

31 Methods. A modified two-round Delphi survey was first used to construct quality indicators on a

32 nine-point Likert scale. With those indicators, the rank sum ratio (RSR) method was then

33 conducted through rank conversion and parametric statistics, to assess and classify the

34 performance of ten districts or counties randomly chosen both from demonstration and non-

35 demonstration districts in the Hunan province.

36 Results. The Delphi process produced 7 themes, 25 sub-themes items as quality indicators. The

377 themes included management of the organization, financial support, professional personnel,

38 health education and promotion, residents' health awareness and behaviors, residents'

39 satisfaction, and residents' health literacy. The districts were classified into four levels by RSR

40 as follows: One demonstration district at the first-ranked level, five other demonstration districts

41 at the second-ranked level, all non-demonstration districts at the third-ranked level. None were at

42 the fourth-qualified level.

43 Discussion. Chronic disease demonstration districts performed better on the work of health

44 education and health promotion than the non-demonstration districts. The work should be

45 focused on the following measures of chronic diseases: management of the organization, 
46 financial support, media-related broadcasting, technical support, community-based promotion

47 and supportive environment, and people's enhanced awareness and health literacy.

\section{1. Introduction}

For some time, chronic diseases, also known as non-communicable diseases (NCDs), have been

the top health threat for Chinese people and now pose an increasing burden of disease (The

National Health and Family Planning Commission of China, 2012; Huang C, Yu H \& Koplan JP, 2014). Currently, 260 million people nationwide are diagnosed with NCDs which are responsible for $85 \%$ of the mortality rate and $70 \%$ of the disease burden in the country (The State Council of China,2012). Thus, the National Health and Family Planning Commission of China (NHFPC) supported a program of NCD demonstration districts (or counties) in 2010, incorporating into both important public health projects for Chinese medical health reform and a work plan of NCD control in China (2012-2015) ( The NHFPC of China, 2012). Since that time, a series of national or provincial NCD demonstration districts have been successively set up across the country. By 2017, thirty-four counties or districts were nominated as NCD demonstration districts in the Hunan province (located in central China), ten of which were nominated as national districts; the rest were nominated as provincial districts (pending approval by the NHFPC).

As cost-effective NCD control strategies (Bayarsaikhan D \& Muiser J, 2007), health education and health promotion also play important roles in the program of NCD demonstration districts. The status of the districts can be directly assessed by their health education and promotion.

66 Nevertheless, considering both advanced strategies and work experiences of health education and

67 promotion in developed countries (Butler JT, 2001; Puska P, 2008; Daniel M et al., 1999), the 
68 strategies and work had a late start in China. To date, very few systematic assessments have been

69 conducted, especially in NCD demonstration districts. The biggest challenge is finding proper

70 quality indicators for the assessments. Without such indicators, it's unclear how well these

71 districts are able to respond to the significant challenges of health education and promotion in

72 their region.

73 Thus, our study was firstly designed to develop quality indicators by the modified

74 RAND/UCLA Delphi method originating from Kathryn Fitch (Fitch K et al., 2001). With these

75 indicators, we were able to get acquainted with the situation of the districts by comparatively

76 assessing the performances between NCD demonstration districts and non-demonstration

77 districts through the rank sum ratio (RSR) technique (Wang $\mathrm{Z}$ et al., 2015), and discover

78 important factors relevant to promote the health education and promotion work.

80 2. Materials and Methods

\section{Study Design}

82 As mentioned above, a modified Delphi combined with the RSR technique was comprehensively

83 used as an evaluation tool and method for this study. Fig.1 shows the overall flow diagram of

84 this study. The Delphi procedure was firstly used to build quality indicators for evaluation of

85 health education and promotion in NCD demonstration districts. The detailed procedure was

86 conducted using the following steps (1-5):

\section{1. Design for consultative indicators}

88 By combining literature review with the related manuals of NCD demonstration districts drafted

89 by the Chinese center for diseases control and prevention (CDC), we modified and designed a

90 38- consultative item for the Delphi process. These items were categorized into seven themes, 
91 including management of organization, financial support, professional personnel, health

92 education and health promotion, heath awareness and behaviors of NCDs , management and

93 control in NCD patients, others (such as satisfaction with supplies of health education and

94 promotion, health literacy level) (Table S1).

\section{2. Selection of experts for Delphi survey}

96 We sent invitations to more than 20 potential experts via e-mail or letter, in which we explained

97 to experts the study background, gave a brief introduction of Delphi method, and what experts

98 needed to do. In total, 19 experts responded and agreed to participate in the Delphi process.

99 Experts across the country were selected for this study using the following criteria:

100 - Be working for the department NCD control and prevention of CDC, health education

101 institution, or public health research (especially on NCDs) in university.

102 - Have had work experience for at least five years at provincial or national institutions.

103 - Be interested in participating in this study.

\section{3. Instrument for Delphi surveys}

105 We listed the instrument for the Delphi surveys as the following four parts:

106 - General characteristics of the experts, including age, profession, professional title, education,

107 years of working experiences and so on.

108 - A basic guideline for finishing the Delphi survey.

109 - Questionnaire with consultative indicators for evaluation of health education and promotion.

110 - Definition of experts' authority both in familiarity with indicators and judgment criteria for

111 the indicators.

\section{4. Two-round Delphi process}


113 With its anonymous consultation, feedback information, statistical inference, and easy utilization

114 (Holbech JV et al., 2017; Kuster K et al., 2015; Gracht H, 2012 ), the Delphi technique is a

115 popular assessment tool in health care research (Zhao ZG et al., 2015; Balaguer A et al., 2016;

116 Jones J \& Hunter D, 1995). We conducted a two-round Delphi process between late 2013 and

1172014 as follows: During round 1, the experts needed to judge whether the items should be

118 included based on validity and feasibility and were free to make comments. They also rated each

119 item for importance on a 9-point Likert scale (Mrowietz U et al., 2014; Suzuki Y et al., 2012).

120 The scores from 1 to 9 correlate to "strongly unimportant" to "strongly important", while 0

121 indicates disagreement.

122 The data from the round 1 were then summarized, revised, and resubmitted for round 2,

123 following the same format as round 1 to determine quality indicators.

\section{5. Consensus definition}

125 The expert agreement, average scores, and coefficient of variance (CV) are internationally taken

126 as common parameters for determining consensus in the Delphi process. However, there are

127 controversies regarding the parameter thresholds (Hasson F, Keeney S \& McKenna H, 2010;

128 Flores C, Marshall S \& Cordina M, 2014; Slade SC et al., 2014; Strosberg JR et al., 2015; Jang

129 SI et al., 2015). We integrated the parameters with a modified criterion to avoid important items

130 from potentially being removed.

131 In the first round, consensus level was set as: (1) Expert agreement (\%): Items were removed

132 with agreement $\leq 40 \%$ and included when agreement $\geq 70 \%$. They were considered uncertain

133 when agreement ranged from 40\% to 70\%. (2) Median scores: Items were excluded with scores

$134 \leq 4$, included when scores $\geq 7$, and temporarily included when scores were between 4 and 6 . (3) 
$135 \mathrm{CV}$ : Items were included with $\mathrm{CV}<0.25$. In the second round, consensus was reached only if

136 agreement $\geq 70 \%$, scores $\geq 7$, and $\mathrm{CV}<0.25$.

\section{6. Selection of samples and RSR evaluation}

138 After the Delphi process, ten districts from the Hunan province were selected and coded as

139 samples for assessment with a simple randomizing function. This study conducted data

140 collection from evaluated districts between 2014 and 2015 on schedule, when twenty-eight

141 districts got the nomination in the province. Therefore, we randomly selected six districts or

142 counties representing NCD demonstration districts. Meanwhile, we also randomly chose four

143 districts or counties from the same cities as that of NCD demonstration districts, as control

144 subjects from the rest of the non-demonstration districts in the province.

145 Finally, the RSR method was conducted in 2015 to assess the performance of the sample

146 districts. As a comprehensive evaluation method, the RSR was developed by Tian FD, who also

147 proved its validation and rationality (Sun ZQ \& Tian FD, 1994; Wang Z et al., 2015). The basic

148 theory of the RSR method is that a dimensionless statistical indicator (RSR) is calculated from

149 an $\mathrm{n} \times \mathrm{m}$ matrix through rank conversion (Wang $\mathrm{Z}$ et al., 2015). With the indicator RSR, a

150 parametric statistic by the linear regression equation $\left({ }^{R S R}\right)$ was followed to analyze the RSR

151 distribution. The statuses (worst/best) of evaluated districts were evaluated or classified based on

152 the ${ }^{R \hat{S R}}$. The RSR procedure was carried out here through the following steps:

153 The original values of items were converted to high-quality values. There was no conversion

154 work here due to their natural high-quality characteristics.

155 - Quality indicators within the ten sample districts were ranked based on their original values.

$156 \quad$ All indicators were ranked in ascending order as $R_{i j}(i \leq n, j \leq m)$ 
157 - The RSR was calculated with the equation $R S R_{i}=\frac{\sum_{j=1}^{m} R_{i j}}{m \times n}$.

158 - The distribution of RSR was analyzed based on a Probit (-oriented downward accumulative 159 frequency $(\mathrm{p})$.

160 - A linear regression was set up. Taking ${ }^{R S R_{i}}$ as a dependent variable and $P$ as an independent

161 variable separately, an equation was built using the formula as $R \hat{S R}=a+b \times \operatorname{Pr}$ obit .

162 - With the $R \hat{S} R$, four levels (from best to worst) were classified into and set for the evaluation

163 of the sample districts as follows: level I $\left(<P_{6.681}\right.$, Probit $\left.<3.5\right)$, level II $\left(P_{6.681}:\right.$, Probit: 3.5 :

164 ), level III ( $P_{50}:$, Probit: 5:), and level IV ( $P_{93.319}:$, Probit: $\left.6.5:\right)$ (Sun ZQ \& Xu YY, 165 2014).

\section{Ethical Approval}

167 We received written, voluntary, informed consent when the completed questionnaires from the

168 experts invited by us were submitted. This study was reviewed and approved by the Ethics

169 Committee of Hunan Provincial Centre for Disease Control and Prevention, China

170 (HNCDC/JL31-044: 2013011).

\section{Statistical Analysis}

172 Characteristics of experts were shown as mean \pm SD (standard deviation) and frequency

173 (percentage). Variables resulted from Delphi processes were reported as frequency (percentage),

174 M (Median), Mode and CV. Student's t-test $(\alpha=0.05)$ was applied to test if both Kendall's W

175 and Cronbach's $\alpha$ between the two round Delphi processes are significantly different from each

176 other. In order to verify the $R S R_{i}$ in different districts which were statistically ranked and 
177 classified, an analysis of variance (ANOVA) was used to perform a hypothesis test $(\alpha=0.05)$ on

178 the linear regression fitting.

179 Data was handled and described by Microsoft Excel 2010. The statistical analyses were

180 performed with SPSS 22.0 version (IBM SPSS Inc., Chicago, IL, USA).

181

\section{3. Results}

\section{3.1 Results of the Delphi Process}

184 In total, 19 experts completed each question in both rounds of the Delphi survey. They were

185 working either for NCD control and prevention departments of CDC, health education

186 institutions, or schools of public health in universities. They averaged $44.84 \pm 6.69$ years old,

187 with a mean of $21.37 \pm 7.90$ working years in their current job. In total, $89.5 \%(17 / 19)$ of the

188 experts were recognized as senior doctors. All of the experts had a bachelor's degree of public

189 health, and $63.2 \%(12 / 19)$ of them also had a master's degree (Table 1).

190 In the first round, five items were removed due to $C V$ values $\geq 0.25$, five other items

191 temporarily remained either because of the agreement between $40 \%$ and $60 \%$, or of scores

192 between 4 and 6 (Table 2). Thirty-three items remained and were merged into thirty-one items in

193 response to experts' opinions. In the second round, five items were removed either because of

194 the agreement $<70 \%$ or of median scores unqualified. Two items were merged into one item

195 (Table 3). Finally, twenty-five items were included in the framework of the quality indicators,

196 including the following themes: management of the organization, financial support, professional

197 personnel, health education and health promotion, residents' health awareness and behaviors of

198 NCDs, residents' satisfaction with supplies from health education and health promotion, and the

199 health literacy of the resident (Table 4). 
200 The Kendall's W was 0.35 in round 1 and 0.45 in round 2, with a significant difference

$201(P<.001)$, showing that no further rounds were needed due to adequate item agreement among

202 the experts. Meanwhile, we used Cronbach's $\alpha$ to measure the internal consistency of indicators.

203 Our study showed that Cronbach's $\alpha$ was 0.90 in round 1 and 0.85 in round 2, with a 95\%

204 confidence interval (CI) of $0.82-0.95$ and $0.74-0.93$, respectively, showing a good internal

205 constancy of indicators (Benhamou M et al., 2013; Bland JM \& Altman DG, 1997).

\section{$206 \quad 3.2$ Results of Sample Selection}

207 Ten districts or counties were chosen as follows: Six NCD demonstration districts, including one

208 national-nominated demonstration district, namely Furong District (A). Five provincial-

209 nominated demonstration districts, namely Ziyang District (B), Shaodong County (C),

210 Shuangfeng County (D), Luxi County (E), and Yuhua District (F). There were four non-NCD

211 demonstration districts,: Anhua County (G), Xinhua County (H), Xinshao County (I), and Jishou

212 County (J). The original values of twenty-five quality indicators in these districts were collected

213 from field investigations; those are shown in Table S2.

\section{$214 \quad 3.3$ Results of RSR}

215 The RSR procedure was followed to assess and classify the sample districts through both rank

216 conversion and parametric statistics. It showed that the ten sample districts were classified into

217 four levels (from best to worst). The Furong District was at the best level, with the highest $R \hat{S} R$ of

218 0.8687. Five NCD demonstration districts were at the second-best level with RSR ranging from

2190.5100 to 0.7442: Ziyang District, Shaodong County, Shuangfeng County, Lu xi County, and

220 Yuhua District. All four non-demonstration districts were at the third-best level with the RSR

221 ranging from 0.2758 to 0.4643: Anhua County, Xinhua County, Xinshao County, and Jishou

222 County. None of the districts were at the fourth-qualified level (Table 5). 
223

\section{4. Discussion}

225 We comprehensively used two assessment tools by combining the modified Delphi and RSR

226 technique to offset the limitations of a single assessment tool. The modified Delphi method

227 conducted in our study included richer information than the traditional Delphi method.

228 Additionally, it is more flexible in the number of rounds, as the process is closed once a

229

230

231

232

233

234

235

236

237

238

239

240

241

242

243

consensus is reached among experts (van Vliet DC et al., 2016) thus avoiding possible redundant work. The RSR method is a comprehensive evaluation tool for multi-indicators with the advantages of having no data type restrictions or bias of abnormal values (Wang Z et al., 2015; Sun ZQ \& Xu YY, 2014; Wang H, Song P \& An L, 2015).

This study showed that the ten sample districts belonged to the first three levels of health education and health promotion, with none at the fourth-qualified level. This indicated that a negative situation for health education and health promotion did not exist in Hunan province.

Overall, NCD demonstration districts performed better in health education and health promotion than non-NCD demonstration districts. The first contributing factor to better performances in the NCD demonstration districts was management of the organization. All NCD demonstration districts had a local government and/or health authority-based leadership team on NCD control, compared to zero teams in non-demonstration districts. This was related to the nature of the programs of NCD demonstration districts in China. The programs were run by the local governments of each district in China (The NHFPC of China, 2016). The support of the local governments was crucial to the success of the program. Their attention shows not only in setting up a leadership team but often in providing more financial support, another factor differing greatly between NCD demonstration districts and non-demonstration districts in this study. 
246 Whether it is the amount of NCD special funds from the government or the proportion of NCD

247 expenditures in total expenses in CDC, the financial support in NCD demonstration districts

248 greatly exceeded those of non-NCD demonstration districts in which no or very few funds were

249 available.

250 The essence of the theme of health education and health promotion in NCD demonstration

251 districts also obviously surpassed that of non-demonstration districts. This was reflected in their

252 development of health broadcasting planning, periodic promotions of NCD control

253 recommendations in media, public consultation of NCD core information, the frequency of

254 updating NCD control recommendations on bulletin boards in the community, and community-

255 based coverage of fitness centers. Actions such as systematic and frequent media propaganda and

256 community-based supportive environment were often canceled or poorly conducted due to

257 insufficient funds. The NCD demonstration districts in this study (except Luxi County) all had

258 more economic resources than non-NCD districts, and three of these NCD demonstration

259 districts (50\%) were urban-level districts. Although Luxi is a national poverty-stricken county

260 (The State Council of China, 2011), it still received a special fund from the local government

261 every year because of the NCD demonstration district program. Meanwhile, the four control

262 subjects were all rural-level districts, $75 \%$ of which were national poverty-stricken counties (The

263 State Council of China, 2011). Another contributing factor is the lower focus on NCD control

264 and prevention in China. Compared to other public health problems such as infectious diseases

265 and public health emergencies, NCD control is still inadequately addressed across the country

266 despite the increased attention it has received (Chen JY, 2015; USA CDC, 2015). Thus, even

267 though a lot of health education and promotion work, such as technical support and community-

268 based promotion, has been conducted in some districts, there has been little focus on NCD 
269 control and prevention. Additionally, the lack of a reward and punishment system based on

270 systematic evaluation was also a possible factor contributing to the differences.

271 An interesting result from this study was that although both the people's awareness rate and

272 health literacy of NCD control and prevention were higher in NCD demonstration districts than

273 in non-demonstration districts, the rate of people's healthy behavior towards NCD control in

274 demonstration districts had a narrow difference from that of non-demonstration districts. This

275 result indicated that there is still a long way to go from people's awareness to healthy behavior.

276 The six demonstration districts were still at two levels. Furong District was the only subject at

277 the best level with many best-performing indicators, especially in terms of financial support and

278 technical support for NCD-related promotion materials, and people's indicators of NCD control,

279 such as health awareness, healthy behaviors, health literacy, and satisfaction with supplies of

280 health education and promotion. Its level of performance benefitted from advantages both in the

281 form of a robust economy (i.e., downtown in the capital city of Hunan) and a historically strong

282 foundation in health education and health promotion. It is worth discussing the second

283 advantage: Furong District had launched a famous “Ten Health" project before the program of

284 NCD demonstration district. The "Ten Health" project was rich in content, including overall

285 health mobilization, massive health lecture, etc. The district had also built a community-based

286 NCD control database and information sharing model. These actions indeed benefitted the

287 residents. This could explain the best-performance of the aforementioned people's health

288 indicators in the Furong District.

289 Limitations

290 One limitation of this study was that the number of evaluated samples (both NCD demonstration

291 districts and non-demonstration districts) was inadequate due to some restrictions such as 
292 insufficient funding, few NCD demonstration districts available during the study period. This

293 might fail to fully represent the whole status of Hunan. Another limitation was that the

294 assessment in this study was based on retrospective data of the evaluated samples, thus, it failed

295 to reflect on the real-time situation of the sample districts, or account for the potential for more

296 non-demonstration districts to join the program of NCD demonstration districts in the future.

\section{Conclusions}

With the integrated Delphi and RSR method, we assessed health education and health promotion work, which is an important part of the NCD demonstration district program in China. We comprehensively and comparatively assessed their performance both in NCD demonstration districts and non-demonstration districts. Our study showed that NCD demonstration districts performed better in health education and health promotion work than non-demonstration districts. To promote this work, emphasis should be placed on the management of organizations in government, financial support, media-related health broadcasting and promotion, publicity materials-based technical support, community-based health promotion and supportive environments, and people's enhanced awareness and health literacy of NCD control.

\section{Acknowledgments}

310 We thank all experts for their participation in the Delphi process. We also extend our thanks to

311 the following CDCs for their assistance in data collection and survey conduction: Furong District

312 CDC, Yuhua District CDC, Ziyang District CDC, Shaodong County CDC, Shuang feng County

313 CDC, Luxi County CDC, Anhua County CDC, Xinhua County CDC, Xinshao County CDC, and 
314 Jishou County. Both Dr. Zundong Yin (MD in Epidemiology and Biostatistics) from the

315 Department of National Immunization Program of the Chinese CDC, and Dr. Fuqiang Liu (MD

316 in Epidemiology and Biostatistics) from Hunan Provincial CDC were highly appreciated for their

317 suggestions on this paper.

318

319 References

320 1. Bureau of Diseases Prevention and Control of the NHPFC. 2012. Circular of Releasing a

321 Work Program for Chronic Diseases Control and Prevention in China (2012-2015).

$322 \quad$ Available at

323 http://www.nhfpc.gov.cn/jkj/s5878/201205/167d45ff9ec7492bb9a4e2a5d283e72c.shtml

324 (accessed 15 April 2018).

325 2. Huang C, Yu H, Koplan JP. 2014. Can China diminish its burden of non-communicable

326 diseases and injuries by promoting health in its policies, practices, and incentives? Lancet

327 384:783-792. DOI: 10.1016/S0140-673661214-9.

328 3. The State Council Information Office of the People's Republic of China. 2012. A White

329 Paper on the Medical and Health Services in China (2012). Available at

330 http://www.scio.gov.cn/zfbps/ndhf/2012/Document/1261878/1261878.htm (accessed 15

331 April 2018).

332 4. Bayarsaikhan D, Muiser J. 2007. Financing Health Promotion (Discussion Paper). Geneva:

333 World Health Organization.

334 5. Butler JT. 2001. Principles of Health Education and Health Promotion, 3rd ed. Belmont, 335 CA: Wadsworth. ISBN: 9780534523749.

336 6. Puska P. 2008. The North Karelia Project: 30 years successfully preventing chronic diseases.

337 Diabetes Voice 53:26-29.

338 7. Daniel M, Green LW, Marion SA, Gamble D, Herbert CP, Hertzman C, Sheps SB. 1999.

339 Effectiveness of community-directed diabetes prevention and control in a rural aboriginal

340 population in British Columbia, Canada. Social Science \& Medicine 48:815-832.

341 https://doi.org/10.1016/S0277-9536 (98)00403-1. 
342 8. Fitch K, Bernstein SJ, Aguilar MD, Burnand B, LaCalle JR, Lazaro P, van het Loo M,

343

344

345

346

347

348

349

350

351

352

353

354

355

356

357

358

359

360

361

362

363

364

365

366

367

368

369

370

371

372
McDonnell M, Vader JP, Kahan JP. 2001. The RAND/UCL Appropriateness Method User's Manual. Santa Monica: RAND Corporation. ISBN: 0-8330-2918-5.

9. Wang Z, Dang S, Xing Y, Li Q, Yan H. 2015. Applying Rank Sum Ratio (RSR) to the Evaluation of Feeding Practices Behaviors, and Its Associations with Infant Health Risk in Rural Lhasa, Tibet. International Journal of Environmental Research and Public Health 12:15173-15181. DOI: 10.3390/ijerph121214976.

10. Holbech JV, Jung A, Jonsson T, Wanning M, Bredahl C, Bach FW. 2017. Combination treatment of neuropathic pain: Danish expert recommendations based on a Delphi process. Journal of Pain Research 10:1467-1475. DOI:10.2147/JPR.S138099.

11. Kuster K, Cousin ME, Jemmi T, Schüpbach-Regula G, Magouras I. 2015. Expert opinion on the perceived effectiveness and importance of on-farm biosecurity measures for cattle and swine farms in Switzerland. PLoS ONE 10: e0144533. DOI: 10.1371/journal.pone.0144533.

12. Gracht H. 2012. Consensus measurement in Delphi studies: Review and implications for future quality assurance. Technological Forecasting and Social Change 79:1525-1536. DOI:10.1016/j.techfore.2012.04.013.

13. Zhao ZG, Cheng JQ, Xu SL, Hou WL, Richardus JH. 2015. A quality assessment index framework for public health services: A Delphi study. Public Health 129:43-51. DOI: 10.1016/j.puhe.2014.10.016.

14. Balaguer A, Monforte-Royo C, Porta-Sales J, Alonso-Babarro A, Altisent R, AradillaHerrero A, Bellido-Pérez M, Breitbart W, Centeno C, Cuervo MA, Deliens L, Frerich G, Gastmans C, Lichtenfeld S, Limonero JT, Maier MA, Materstvedt LJ, Nabal M, Rodin G, Rosenfeld B, Schroepfer T, Tomás-Sábado J, Trelis J, Villavicencio-Chávez C, Voltz R. 2016. An international consensus definition of the wish to hasten death and its related factors. PLoS ONE 11: e0146184. DOI: 10.1371/journal.pone.0146184.

15. Jones J, Hunter D. 1995. Consensus methods for medical and health services research. $B M J$ 311: 376-380.

16. Mrowietz U, de Jong EM, Kragballe K, Langley R, Nast A, Puig L, Reich K, Schmitt J, Warren RB. 2014. A consensus report on appropriate treatment optimization and transitioning in the management of moderate-to-severe plaque psoriasis. Journal of the European Academy of Dermatology and Venereology 28: 438-453. DOI: 10.1111/jdv.12118. 
373 17. Suzuki Y, Fukasawa M, Nakajima S, Narisawa T, Kim Y. 2012. Development of disaster

374

375

376

377

378

379

380

381

382

383

384

385

386

387

388

389

390

391

392

393

394

395

396

397

398

399

400

401

402 mental health guidelines through the Delphi process in Japan. International Journal of Mental Health Systems 6:7. DOI: 10.1186/1752-4458-6-7.

18. Hasson F, Keeney S, McKenna H. 2010. Research guidelines for the Delphi survey technique. Journal of Advanced Nursing 32:1008-1015.

DOI: https://doi.org/10.1046/j.1365-2648.2000.t01-1-01567.x

19. Flores C, Marshall S, Cordina M. 2014. Use of the Delphi technique to determine safety features to be included in a neonatal and paediatric prescription chart. International Journal of Clinical Pharmacy 36:1179-1189. DOI: 10.1007/s11096-014-0014-y.

20. Slade SC, Dionne CE, Underwood M, Buchbinder R. 2014. Standardised method for reporting exercise programmes: Protocol for a modified Delphi study. BMJ Open. 4: e006682. DOI: 10.1136/bmjopen-2014-006682.

21. Strosberg JR, Fisher GA, Benson AB, Anthony LB, Arslan B, Gibbs JF, Greeno E, Iyer RV, Kim MK, Maples WJ, Philip PA, Wolin EM, Cherepanov D, Broder MS. 2015. Appropriateness of systemic treatments in unresectable metastatic well-differentiated pancreatic neuroendocrine tumors. World Journal of Gastroenterolog 21: 2450-2459. DOI: 10.3748/wjg.v21.i8.2450.

22. Jang SI, Cho KH, Kim SJ, Lee KS, Park EC. 2015. Setting a health policy research agenda for controlling cancer burden in Korea. Cancer Research and Treatment 47:149-157. DOI: 10.4143/crt.2013.167.

23. Sun ZQ, Tian FD. 1994. Medical Systematic Evaluation. Beijing: China Science and Technology Press. (In Chinese).

24. Sun ZQ, Xu YY. 2014. Medical Statistics, 4th ed. Beijing: People Medical Publishing House, 419-421. ISBN 978-7-117-19109-8. (In Chinese).

25. Benhamou M, Baron G, Dalichampt M, Boutron I, Alami S, Rannou F, Ravaud P, Poiraudeau S. 2013. Development and validation of a questionnaire assessing fears and beliefs of patients with knee osteoarthritis: The Knee Osteoarthritis Fears and Beliefs Questionnaire (KOFBeQ). PLoS ONE 8: e53886. DOI: 10.1371/journal.pone.0053886.

26. Bland JM, Altman DG. 1997. Statistics Notes: Cronbach's Alpha. London: BMJ, 314:572. DOI: https://doi.org/10.1136/bmj.314.7080.572 
403 27. van Vliet DC, van der Meij E, Bouwsma EV, Vonk Noordegraaf A, van den Heuvel B, 404 Meijerink WJ, van Baal WM, Huirne JA, Anema JR. 2016. A modified Delphi method 405 toward multidisciplinary consensus on functional convalescence recommendations after 406 407 408 409 abdominal surgery. Surgical Endoscopy 30: 5583-5595. DOI: 10.1007/s00464-016-4931-9.

28. Wang H, Song P, An L. 2015. Comprehensive Evaluation of the Situation of Maternal

29. The National Health and Family Planning Commission of China. Notice on the National
Management of the Program of NCD Demonstration Plot in China (2016). Available at

29. The National Health and Family Planning Commission of China. Notice on the National
Management of the Program of NCD Demonstration Plot in China (2016). Available at Health Care with TOPSIS and RSR. Chinese Journal of Health Statistics 32: 240-242. (In Chinese) http://www.nhfpc.gov.cn/jkj/s5878/201611/6d55c194a965460b9bc7ee9cb5cb4592.shtml (accessed 15 April 2018).

30. The State Council Leading Group Office of Poverty Alleviation and Development of China, the National Development and Reform Commission. 2011. Notice on the Printing and Distribution of the Plan of Wuling Mountain Area Regional Development and Poverty Alleviation (2011-2020). Available at http://www.ndrc.gov.cn/zcfb/zcfbqt/201304/t20130425_538575.html (accessed 15 April 2018).

31. Chen JY. 2015. It should bring the normal state into the control and prevention of chronic diseases. China Hospital CEO 90. (In Chinese)

32. USA Centers for Disease Control and Prevention. 2015. Addressing Noncommunicable Diseases in China. Available at https://www.cdc.gov/globalhealth/stories/ncd_china.htm 425 
Figure 1

\section{The overall flow diagram of this study design}

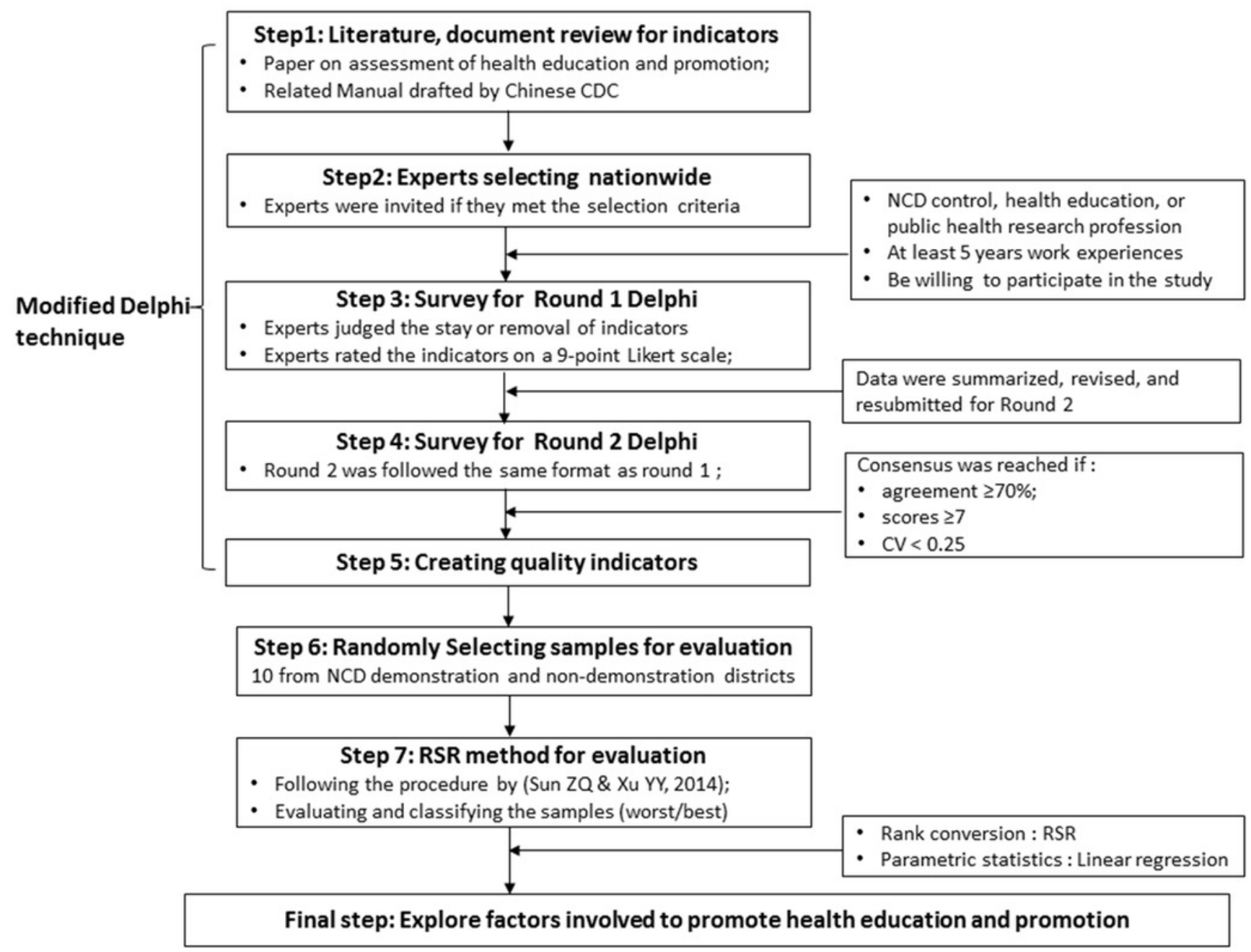




\section{Table 1 (on next page)}

The description of experts participating in the study 
1 Table 1. The description of experts participating in the study.

\begin{tabular}{|c|c|c|c|}
\hline Items & Sub-Items & $N(n=19)$ & $\%$ \\
\hline \multirow{4}{*}{ Age (yr.) } & $<40$ & 4 & 21.05 \\
\hline & $40-49$ & 11 & 57.89 \\
\hline & $50-59$ & 3 & 15.79 \\
\hline & $\geq 60$ & 1 & 5.26 \\
\hline \multirow{3}{*}{$\begin{array}{l}\text { professional title } \\
\text { (public health) }\end{array}$} & *Chief doctor or professor & 10 & 52.63 \\
\hline & $\begin{array}{l}\text { *Associate chief doctor or associate } \\
\text { professor }\end{array}$ & 7 & 36.84 \\
\hline & Attending doctor & 2 & 10.53 \\
\hline \multirow{3}{*}{ Academic degree } & MD & 6 & 31.58 \\
\hline & Master & 6 & 31.58 \\
\hline & Bachelor & 7 & 36.84 \\
\hline \multirow{3}{*}{ Professional background } & NCD control and prevention & 10 & 52.63 \\
\hline & Health education and health promotion & 6 & 31.58 \\
\hline & Public health & 3 & 15.79 \\
\hline \multirow{4}{*}{ Years in current job } & $5-9$ & 3 & 15.79 \\
\hline & $10-19$ & 11 & 57.89 \\
\hline & $20-29$ & 4 & 21.05 \\
\hline & $\geq 30$ & 1 & 5.26 \\
\hline
\end{tabular}

$2 \mathrm{MD}=$ Doctor of medicine. $\mathrm{NCD}=$ Non-communicable disease.

$3 *$ equivalent for both. 
Table 2 (on next page)

Results from the round 1 Delphi process in this study. 
1 Table 2 Results from the round 1 Delphi process in this study.

\begin{tabular}{|c|c|c|c|c|c|}
\hline Themes & Seq. & Agreement (\%) & Median & Mode & $C V$ \\
\hline \multirow{4}{*}{ Management of organization } & 1 & 100.00 & 9 & 9 & 0.11 \\
\hline & 2 & 78.95 & 8 & 8 & 0.14 \\
\hline & 3 & 100.00 & 8 & 9 & 0.18 \\
\hline & $4 *$ & 89.47 & 6 & 8 & 0.28 \\
\hline \multirow{3}{*}{ Financial support } & 5 & 100.00 & 9 & 9 & 0.07 \\
\hline & 6 & 78.95 & 8 & 9 & 0.19 \\
\hline & 7 & 89.47 & 8 & 8 & 0.15 \\
\hline \multirow{2}{*}{ Professional personnel } & 8 & 89.47 & 7 & 8 & 0.15 \\
\hline & $9 *$ & 68.42 & 6 & 6 & 0.30 \\
\hline \multirow{19}{*}{$\begin{array}{l}\text { Health education and health } \\
\text { promotion }\end{array}$} & 10 & 100.00 & 8 & 8 & 0.12 \\
\hline & 11 & 100.00 & 8 & 8 & 0.12 \\
\hline & 12 & 100.00 & 7 & 8 & 0.18 \\
\hline & 13 & 94.74 & 7 & 7 & 0.19 \\
\hline & 14 & 84.21 & 7 & 6 & 0.17 \\
\hline & 15 & 84.21 & 7 & 6 & 0.16 \\
\hline & 16 & 78.95 & 6 & 6 & 0.18 \\
\hline & 17 & 78.95 & 7 & 7 & 0.17 \\
\hline & 18 & 94.74 & 6 & 6 & 0.17 \\
\hline & 19 & 68.42 & 6 & 5 & 0.23 \\
\hline & 20 & 94.74 & 7 & 6 & 0.20 \\
\hline & 21 & 89.47 & 7 & 6 & 0.19 \\
\hline & 22 & 100.00 & 8 & 8 & 0.13 \\
\hline & 23 & 100.00 & 7 & 7 & 0.23 \\
\hline & 24 & 94.74 & 7 & 7 & 0.22 \\
\hline & 25 & 94.74 & 7.5 & 8 & 0.15 \\
\hline & 26 & 94.74 & 7.5 & 7 & 0.15 \\
\hline & 27 & 47.37 & 6 & 6 & 0.24 \\
\hline & 28 & 47.37 & 6 & 6 & 0.22 \\
\hline \multirow{2}{*}{$\begin{array}{l}\text { Awareness and behavior of } \\
\text { NCDs }\end{array}$} & 29 & 100.00 & 8 & 9 & 0.19 \\
\hline & 30 & 68.42 & 8 & 9 & 0.21 \\
\hline \multirow{4}{*}{$\begin{array}{l}\text { Management and control in NCD } \\
\text { patients }\end{array}$} & $31 *$ & 52.63 & 6.5 & 9 & 0.27 \\
\hline & 32 & 68.42 & 8 & 9 & 0.19 \\
\hline & $33 *$ & 42.11 & 7 & 7 & 0.26 \\
\hline & 34 & 52.63 & 7 & 7 & 0.18 \\
\hline \multirow{4}{*}{ Other } & 35 & 68.42 & 8 & 8 & 0.17 \\
\hline & 36 & 94.74 & 7.5 & 9 & 0.24 \\
\hline & $37 *$ & 73.68 & 6 & 6 & 0.26 \\
\hline & 38 & 100.00 & 7 & 8 & 0.23 \\
\hline Total & - & - & 7 & 8 & 0.20 \\
\hline
\end{tabular}

2 * Items removed from the process. $\mathrm{CV}=$ Coefficient of variation. 


\section{Table 3 (on next page)}

Results from the round 2 Delphi process in this study. 
1 Table 3 Results from the round 2 Delphi process in this study.

\begin{tabular}{|c|c|c|c|c|c|}
\hline Themes & Seq. & Agreement (\%) & $M(s)$ & Mode & $C V$ \\
\hline \multirow{4}{*}{ Management of organization } & 1 & 100.00 & 9 & 9 & 0.15 \\
\hline & 2 & 73.68 & 8 & 8 & 0.20 \\
\hline & 3 & 100.00 & 8 & 9 & 0.15 \\
\hline & $4 *$ & - & - & - & - \\
\hline \multirow{3}{*}{ Financial support } & 5 & 100.00 & 9 & 9 & 0.05 \\
\hline & 6 & 89.47 & 8 & 9 & 0.18 \\
\hline & 7 & 89.47 & 8 & 8 & 0.11 \\
\hline \multirow{2}{*}{ Professional personnel } & 8 & 94.74 & 8 & 8 & 0.12 \\
\hline & $9 *$ & - & - & - & - \\
\hline \multirow{19}{*}{$\begin{array}{l}\text { Health education and health } \\
\text { promotion }\end{array}$} & 10 & 100.00 & 8 & 8 & 0.09 \\
\hline & 11 & 100.00 & 8 & 8 & 0.09 \\
\hline & 12 & 100.00 & 7 & 8 & 0.18 \\
\hline & $13 * *$ & - & - & - & - \\
\hline & 14 & 84.21 & 7 & 7 & 0.16 \\
\hline & $15 * * *$ & 78.95 & 6 & 7 & 0.16 \\
\hline & 16 & 78.95 & 7 & 7 & 0.16 \\
\hline & 17 & 94.74 & 7 & 6 & 0.15 \\
\hline & $18 * * *$ & 89.47 & 6 & 6 & 0.17 \\
\hline & $19 * *$ & - & - & - & - \\
\hline & 20 & 94.74 & 7 & 7 & 0.16 \\
\hline & 21 & 89.47 & 7 & 7 & 0.20 \\
\hline & 22 & 100.00 & 8 & 8 & 0.09 \\
\hline & 23 & 94.74 & 7 & 7 & 0.18 \\
\hline & 24 & 89.47 & 7 & 7 & 0.16 \\
\hline & 25 & 100.00 & 8 & 9 & 0.14 \\
\hline & 26 & 94.74 & 8 & 9 & 0.13 \\
\hline & $27 * * *$ & 57.89 & 7 & 7 & 0.22 \\
\hline & $28 * * *$ & 52.63 & 7 & 7 & 0.22 \\
\hline \multirow{2}{*}{$\begin{array}{l}\text { Awareness and behavior of } \\
\text { NCDs }\end{array}$} & 29 & 100.00 & 8 & 8 & 0.08 \\
\hline & 30 & 73.68 & 8 & 8 & 0.17 \\
\hline \multirow{4}{*}{$\begin{array}{l}\text { Management and control in } \\
\text { NCD patients }\end{array}$} & $31 *$ & - & - & - & - \\
\hline & $32 * * *$ & 68.42 & 7 & 7 & 0.20 \\
\hline & $33 *$ & - & - & - & - \\
\hline & $34 * * *$ & 47.37 & 6 & 6 & 0.12 \\
\hline \multirow{4}{*}{ Other } & 35 & 78.95 & 7 & 7 & 0.18 \\
\hline & 36 & 100.00 & 7 & 7 & 0.15 \\
\hline & $37 *$ & - & - & - & - \\
\hline & 38 & 94.74 & 8 & 8 & 0.14 \\
\hline Total & - & - & 8 & 8 & 0.16 \\
\hline
\end{tabular}




\section{Table 4 (on next page)}

Framework of quality indicators for evaluation of health education and health promotion 
Table 4. Framework of quality indicators for evaluation of health education and promotion

\begin{tabular}{|c|c|c|}
\hline Subject items & Sub-subject items & Code \\
\hline \multirow{3}{*}{$\begin{array}{l}\text { Management of } \\
\text { organization }\end{array}$} & Local government based leadership team on NCDs control was established and held meetings once at least per year & 1 \\
\hline & Local health authority based leadership team on NCDs control was established and held meetings once at least per year & 2 \\
\hline & whether a yearly work plan on health education and promotion of NCDs was made & 3 \\
\hline \multirow[t]{3}{*}{ Financial support } & the number of NCDs special fund by local government per thousand population per year (RMB, yuan) & 4 \\
\hline & the number of NCDs control expenditures in local CDC (ten thousand yuan) & 5 \\
\hline & the proportion of NCDs control expenditures in total business expenses in local CDC (\%) & 6 \\
\hline Professional personnel & the number of persons in NCDs health education and promotion institutions beyond village level per thousand population & 7 \\
\hline \multirow{13}{*}{$\begin{array}{l}\text { Health education and } \\
\text { health promotion }\end{array}$} & whether a yearly NCDs related health broadcasting planning was developed & 8 \\
\hline & Whether billboards on NCDs control were presented and advertised regularly in local medias (except TV) & 9 \\
\hline & the frequencies and average minutes (per time )of promotion on NCDs control and prevention in local TV station per year & 10 \\
\hline & the mean sorts of materials printed and promotion billboards of NCDs control and prevention & 11 \\
\hline & the mean sorts of NCDs control and prevention video presented by town level hospitals & 12 \\
\hline & the times of public consultation of NCDs related core information on different themes per year & 13 \\
\hline & the community based coverage of NCDs control and prevention billboard (\%) & 14 \\
\hline & the average monthly frequencies of NCDs control and prevention billboard updating in community & 15 \\
\hline & the average coverage of fitness center or room in community $(\%)$ & 16 \\
\hline & the times of NCDs related health lecture in community（a scale of $>50$ persons $)$ & 17 \\
\hline & the times of massive promotion activities of NCDs per year（a scale of >100 persons) & 18 \\
\hline & the institution based coverage of NCDs control lectures in both elementary and middle school (\%) & 19 \\
\hline & the students based coverage of NCDs control lectures in both elementary and middle school (\%) & 20 \\
\hline \multirow{2}{*}{$\begin{array}{l}\text { Heath awareness and } \\
\text { behaviors of NCDs }\end{array}$} & people's awareness rate of NCDs control and prevention (\%) & 21 \\
\hline & the rate of people's healthy behavior formation(\%) & 22 \\
\hline \multirow[t]{3}{*}{ Others } & Whether the assessments of NCDs risk factors had been conducted during the past 3 years & 23 \\
\hline & people's satisfaction with supplies of health education and promotion & 24 \\
\hline & people's health literacy level in NCDs control and prevention & 25 \\
\hline
\end{tabular}

1 


\section{Table 5 (on next page)}

The result from the evaluated districts with the Rank Sum Ratio method. 
1 Table 5. The result from the evaluated districts with the Rank Sum Ratio method.

\begin{tabular}{llllllll}
\hline Code & RSR & $\boldsymbol{f}$ & $\bar{R}$ & $\boldsymbol{p}$ & Probit & $R \hat{S} R$ & Classification* \\
\hline A & 0.8173 & 1 & 10 & 97.5 & 6.96 & 0.8687 & $\mathrm{~A}$ \\
F & 0.7577 & 1 & 9 & 90 & 6.28 & 0.7442 & $\mathrm{~B}$ \\
$\mathrm{~B}, \mathrm{C}$ & 0.6635 & 2 & 7.5 & 75 & 5.67 & 0.6326 & $\mathrm{~B}$ \\
$\mathrm{E}$ & 0.6192 & 1 & 6 & 60 & 5.25 & 0.5558 & $\mathrm{~B}$ \\
$\mathrm{D}$ & 0.6019 & 1 & 5 & 50 & 5.00 & 0.5100 & $\mathrm{~B}$ \\
$\mathrm{H}$ & 0.3846 & 1 & 4 & 40 & 4.75 & 0.4643 & $\mathrm{C}$ \\
$\mathrm{I}$ & 0.3558 & 1 & 3 & 30 & 4.48 & 0.4148 & $\mathrm{C}$ \\
$\mathrm{J}$ & 0.3365 & 1 & 2 & 20 & 4.16 & 0.3563 & $\mathrm{C}$ \\
$\mathrm{G}$ & 0.2904 & 1 & 1 & 10 & 3.72 & 0.2758 & $\mathrm{C}$ \\
\hline
\end{tabular}

$2 \mathrm{RSR}=$ Rank Sum Ratio; * A to C: best-ranked to third-best ranked. 